\title{
Preliminary Study for the Clean Up of Hydrocarbon contaminated Soil Using Soil Washing Mechanism
}

\author{
AL RASHED AHMED ${ }^{1}$, AL MUTAIRI NEYEF ${ }^{2}$, MOSTAGAB HOSSAM $^{3}$ \\ 1. Science department, public Authority of Applied Education and Training, KUWAIT. \\ 2. Department of Civil Engineering, Kuwait University, P.O.Box 5969, 13060, Safat, KUWAIT. \\ 3. Environmental department, Kuwait Oil Company Contractor, KUWAIT.
}

\begin{abstract}
Major oil spills and soil contaminations attracts the attention of its great effects on the Environment elements water, soil and air important part of the spill is to reduce the risk of oil spills, time and effort is highly appreciated in clean up procedures. In march 101991 more than 700 oil wells have been damage by Iraqi troops in Kuwait,71,428,571 tons of oil expelled on land and sea of Kuwait .low cost of cleanup contaminated Raduhtain oil field soil was implemented the authors introduced and used washing the contaminated soil by date seeds technique. This work deals with the treatment of oil-contaminated soil, by using different concentration of date seeds. Soil washing is one of the sustainable technologies at present to remove oil from soil. From lab test, it seems to be an excellent way to treat contaminated soil. Samples of soil and wastewater were taken and analyzed in order to evaluate TOC concentration and removal value. The original TOC values of control water samples in (day 1st, day 3rd and day 5th) are $(319925,319896,319680, \mu \mathrm{g} / \mathrm{g}$ ) respectively. The experiment with $50 \mathrm{~g}$ date seeds in (day 1, day 3 and day 5 ) shows the result are $(275285.7,98714.29$, $91642.8, \mu \mathrm{g} / \mathrm{g}$ ) respectively. Whereas with $100 \mathrm{~g}$ date seed with $100 \mathrm{~g}$ in (day1, day 3 , day 5 ) the TOC concentration is $(289428.57,249642.9,71714.29, \mu \mathrm{g} / \mathrm{g})$ respectively.
\end{abstract}

Keywords: Soil washing, TOC, Date seeds, Contaminated

Received: September 12, 2009. Revised: June 8, 2020. Re-revised: June 17, 2020. 3rd-Revised: June 23, 2020 , Accepted: June 29, 2020. Published: July 1, 2020.

\section{Introduction}

The term "Soil Washing" is misleading as the soil is technically not washed but fractionated into different grain size ranges. It is a process to reduce the volume of waste by sizing and separating particle fractions which have adsorbed the majority of the contamination from the bulk soil fractions. This is facilitated by the fact that most organic contaminants tend to bind to clay and silt due to the fines' higher adsorption capacity (higher specific surface) compared to coarser particles. Supported by mechanical force and chemicals the process separates the fine fractions from the coarser soil particles and simultaneously concentrates the contaminants into the wash solution and into the smaller volume of fine particles. The wash solution and the contaminants concentrated in a smaller volume generally require further treatment by using an additional treatment process or remediation technology (treatment train).Key factor in determining the applicability of soil washing is knowledge of the grain size distribution in the soils to be treated and the proportion of organic compounds which can be mobilized. In general the soil washing process is most effective when applied to soils and sediments containing large proportions of sand and gravel. Soil washing is relatively ineffective when applied to soils with high silt, clay, and organic material levels. Depending on the hardness of the minerals in the processed soils application of mechanical force (e.g., extensive attrition scrubbing, high pressure water jets) may increase the portion of fines. The greatest risk in soil washing operations is that of inaccurate or insufficient soil characterization. 
More than twenty-eight years have passed since the Gulf War in 1991. In Kuwait, rehabilitation has proceeded regularly, and urban areas were fast restored to their prewarfare fame, within the outlying wilderness regions ,massive-scale of environmental pollutants crude oil spilled from more than 700 oil wells destroyed at Kuwait desert. Hundreds of thousands of barrels of crude oil gushed freely from those wells, creating oil lakes in the depressions of desert environment. Lakes shaped 500 specific places, (149 Km2).Most of Kuwait was effected in some ways. considerable damage was done to the infrastructure by the invasion and public surfaces. Desert area soil remain highly contaminated. Contamination result from oil that spread from the discharge of well heads detonated by Iraqi troops, as well as from the areal deposition of partially burned oil combustion production from wells the burned uncontrolled for nine mouths. Much of the oil collected in small topographic depressions in the open areas of Kuwait. Although some consideration was given to the possible consequences of the various forms and other treatments used to put out the oil fires. Total petroleum hydrocarbons (TPHCs) are classified as non-aqueous-phase liquids (NAPL) and are released into the environment from chemical spills among other releases. The problem with large NAPL releases into the soil subsurface is that a percentage of the release will reach the groundwater, causing groundwater contamination by the NAPL. In order to prevent groundwater contamination, it is necessary to remediate the NAPL quickly. Managing these contaminated sites carries significant costs for the assessment, remediation, and long-term monitoring that are required. Some of these contaminated sites are in isolated areas and are difficult to access and therefore difficult to assess and remediate. A method that is frequently used to remediate a site is the excavation of the contaminated material from the site, with the void filled by clean fill. This process is commonly referred to as "dig and dump." Dig and dump is quick and very effective but transports the contamination to another area and changes the natural oil structure of the area, causing a disruption to the local ecosystem (Khan, Husain, and Hejazi 2004). Another remediation method is soil vapor extraction (SVE) that can effectively remove petroleum hydrocarbons from soil in the unsaturated zone. SVE requires the placing of dry wells into the contaminated soil regions and using a pump to extract air out of the unsaturated soil region. This induced vapor flow allows for the faster removal of petroleum hydrocarbon contaminants from the unsaturated soil zone (Khan, Husain, and Hejazi 2004). However, research has shown that mass transfer limitations develop over time, making it difficult to completely remediate a site. This problem is called tailing and is a significant challenge, as the soil still has contaminant levels in excess of the cleanup criteria (Gidda et al. 2006).Kuwait Oil company (KOC) had successfully recovered 22.5 million barrels of the spilled c rude, 22.7 million $(\mathrm{m} 3)$ of contaminated soil left behind, in the ground floor. Pollution remediation was undergoing in the area to treat contaminated soil and prevent groundwater pollution. A pilot plan of Physical /chemical remediation of three common bioremediation methods were tested. Large-scale remediation process had performed, for the best implementation of fullscale remediation. (For 2500 tons of contaminated soil).The purpose of this research is to test cleaning the heavily impacted soil by oil using washing technique with reference to date seeds considering it costs and time.

\subsection{Soil Characteristics of the area:}

Generally, as shown in Fig.(1), the surface of Kuwait is flat sandy desert and divided into north and south regions. In the north where Raudhatain oil field lies, the area is hard flat desert covered with wind below sand[1].

[2] several types of Aeolian deposits in the desert of Kuwait can be recognized: (1)rugged vegetated sand sheets, (2) smooth sand sheets, (3) act rite sand sheet,(4) Aeolian wadi fill, (5) sand dunes and sand drift. Sand sheets are dominated in Raudhatain area and the north part of Kuwait. It is flat to low angle Aeolian stratification, and commonly exist on the margins or between belts of sand dunes. Sand sheets have coarse grains sediments comparing with other deposits in the desert such as dunes or ripples. Sand sheet have unidirectional ripple surface indicating the prevailing North West wind direction. They have flat surface cover with thin veneer of residual granules of course sands and some paths of residual gravel. Figure (2) represents Twenty clean 
samples of soil collected from different localities around the Raudhatain oil field. Soil samples were drying by air and sieve to obtain representative size-samples.

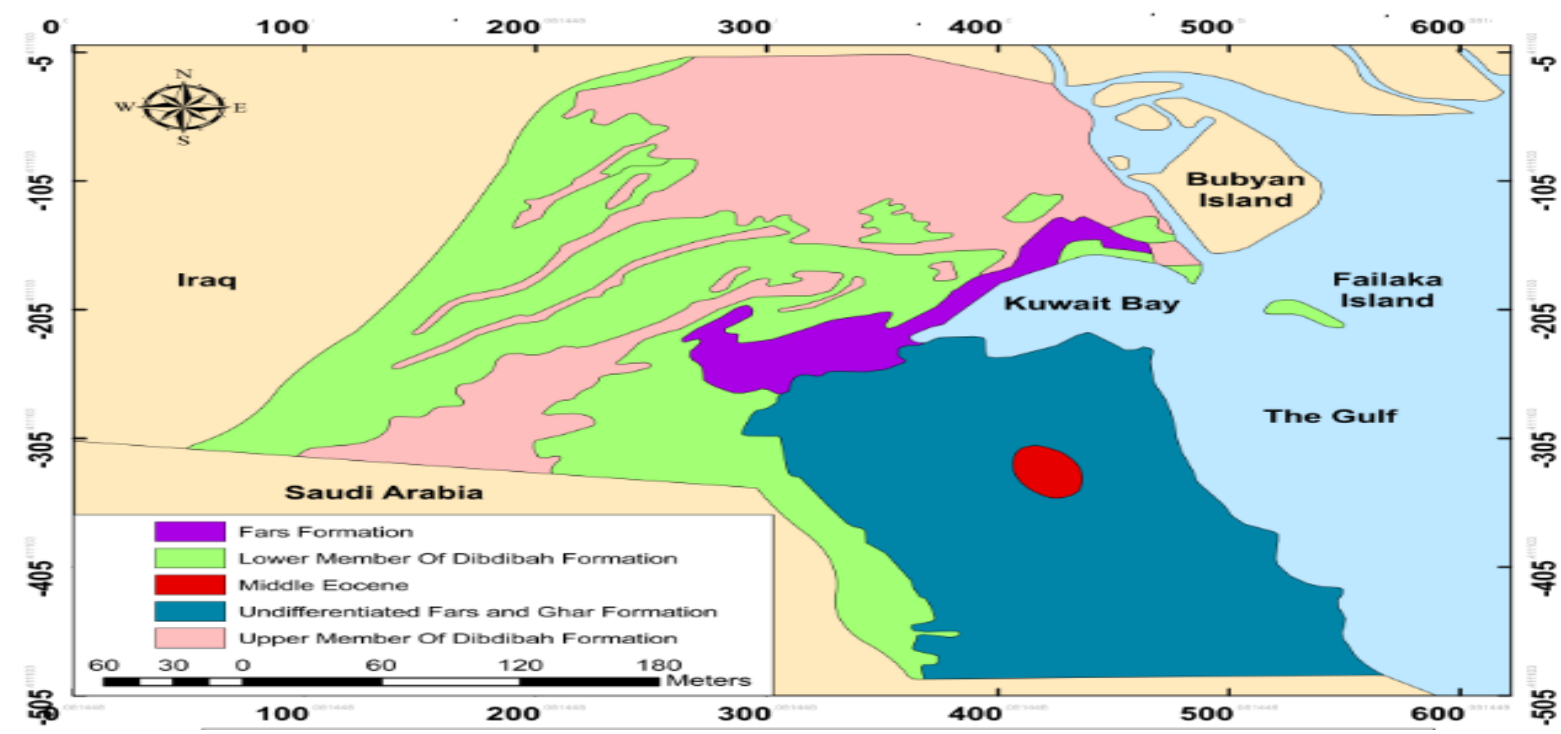

Figure 1 Stratigraphic map of Kuwait, [1].

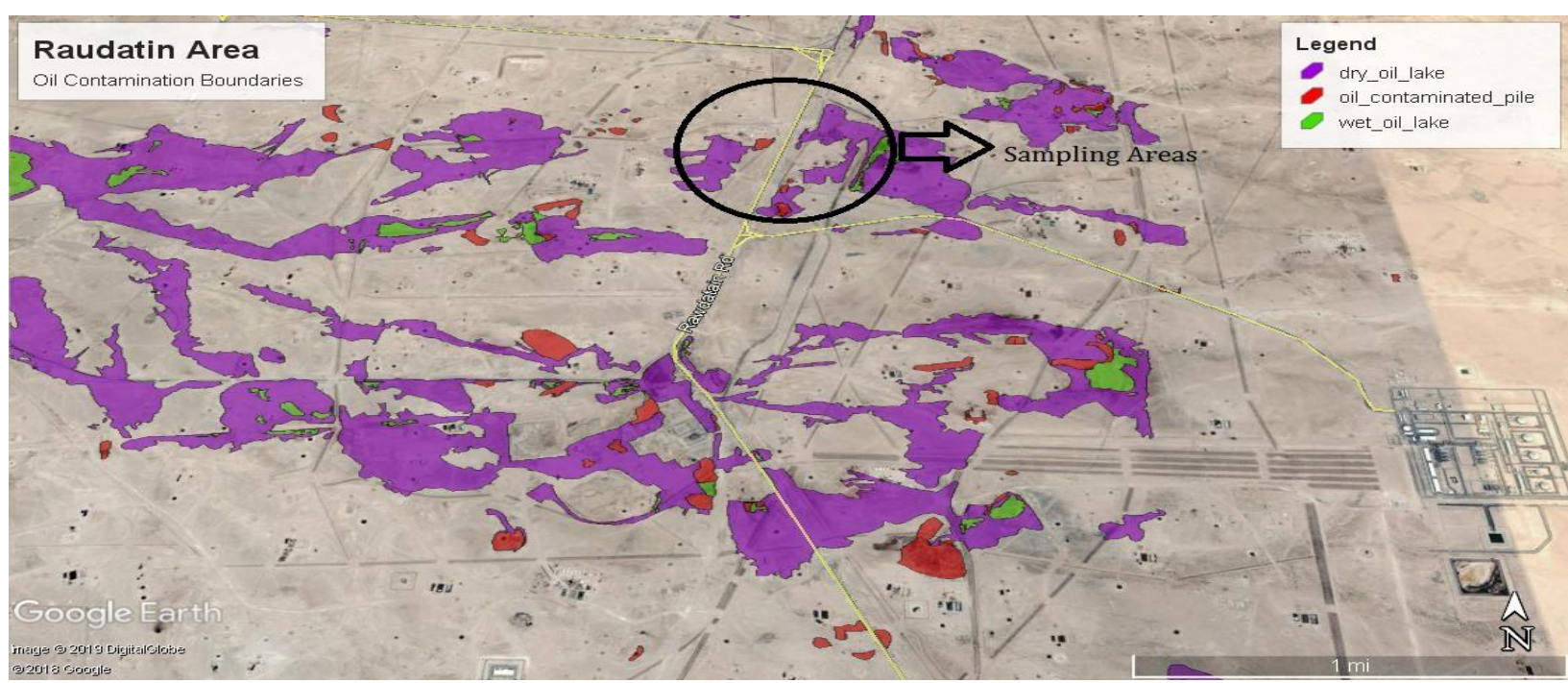

Figure 2. Location map for Raudatinoilfield and Sampling areas[3]. 


\subsection{Date Seeds and Soil washing}

Dates are very popular and stable food in the arid regions in the world [4], [5], [6].Dates are commercially solid and processed into various date products. Dates are consumed in fresh ordered form. Dried dates can be stored around the year for their consumption pericarp for the edible part and a pit considered as by-product and waste [7], [8].

Table 1. Chemical composition of date -pits (g/100g date -pits), [7].

\subsection{Chemical composition of date seeds}

Table (1) demonstrates the chemical composition of different date - pits varieties with moisture content ranging from 3.19/100g date - pits. The average chemical characteristic of these types: acid value $1.04 \%$ iodine value $49.5 \%$. [9].

\begin{tabular}{|l|c|c|c|c|c|}
\hline Variety & Moisture & Fat & Protein & Ash & Carbohydrates \\
\hline Khalas (1) & 7.5 & 10.5 & 5.7 & 1.05 & 78.3 \\
\hline Fard h(2) & 9.5 & 8.2 & 5.8 & 1.2 & 78 \\
\hline Lulu(3) & 10.9 & 10.5 & 5.2 & 0.91 & 74.7 \\
\hline DegletNour(4) & 11.2 & 10.1 & 5.6 & 1.1 & 83.1 \\
\hline Alig(5) & 10.3 & 12.5 & 5.2 & 1.1 & 81 \\
\hline Mabseeli(6) & 3.1 & 5 & 3.9 & 1 & 86.9 \\
\hline Um sellah(7) & 4.4 & 5.9 & 5.4 & 1.2 & 83.1 \\
\hline Shahal(8) & 5.2 & 5.1 & 2.3 & 0.9 & 86.5 \\
\hline Barhe(9) & 10.6 & 7.5 & 5.7 & 1.06 & 75.1 \\
\hline Shikatalkahlas (10) & 9.6 & 7.4 & 5.3 & 0.97 & 76.7 \\
\hline Sokkery (11) & 12.1 & 6.5 & 6.4 & 0.96 & 74 \\
\hline Bomaan(12) & 9.6 & 6.4 & 5.4 & 1.02 & 77.6 \\
\hline Sagay(13) & 12.1 & 5.7 & 5.3 & 0.99 & 77.2 \\
\hline Shishi (14) & 10.4 & 6.2 & 5.7 & 0.94 & 76.8 \\
\hline Maghool(15) & 9.8 & 6.5 & 5.6 & 1.14 & 77 \\
\hline Sultana (16) & 10 & 6.6 & 5.2 & 0.91 & 77.2 \\
\hline Maktoomi (17) & 9.8 & 7.5 & 5.8 & 1.07 & 75.8 \\
\hline Naptisaif(18) & 10.2 & 6.9 & 5.7 & 0.84 & 76.4 \\
\hline Jabri (19) & 9.9 & 7.1 & 5.4 & 0.96 & 76.7 \\
\hline Khodary (20) & 10.2 & 7.7 & 5.4 & 0.87 & 75.9 \\
\hline Dabbas (21) & 12.3 & 6.9 & 5.1 & 0.92 & 74.8 \\
\hline Raziz (22) & 12.5 & 8.8 & 6.9 & 0.99 & 70.9 \\
\hline Shabebe (23) & 11.5 & 7.7 & 4.8 & 1.09 & 75 \\
\hline
\end{tabular}

\subsection{Fatty acids composition of date}

Table (2) presents the fatty acid composition found in dates. Major saturated fatty acid present in dates alone $0.11-38.81 \mathrm{gm}$. /100. This present is varying with other dates types. Palmitoleic acids are the main monsoon started fatty acids while Linoleic are the major polyunsaturated fatty oil Table 2. Fatty Acids composition of dates[7], [8]. with high oleic fatty content with good flavor and frying stability. Date oil have low content of linoleic acid as compared to vegetable oils and lower degree of un saturation. 


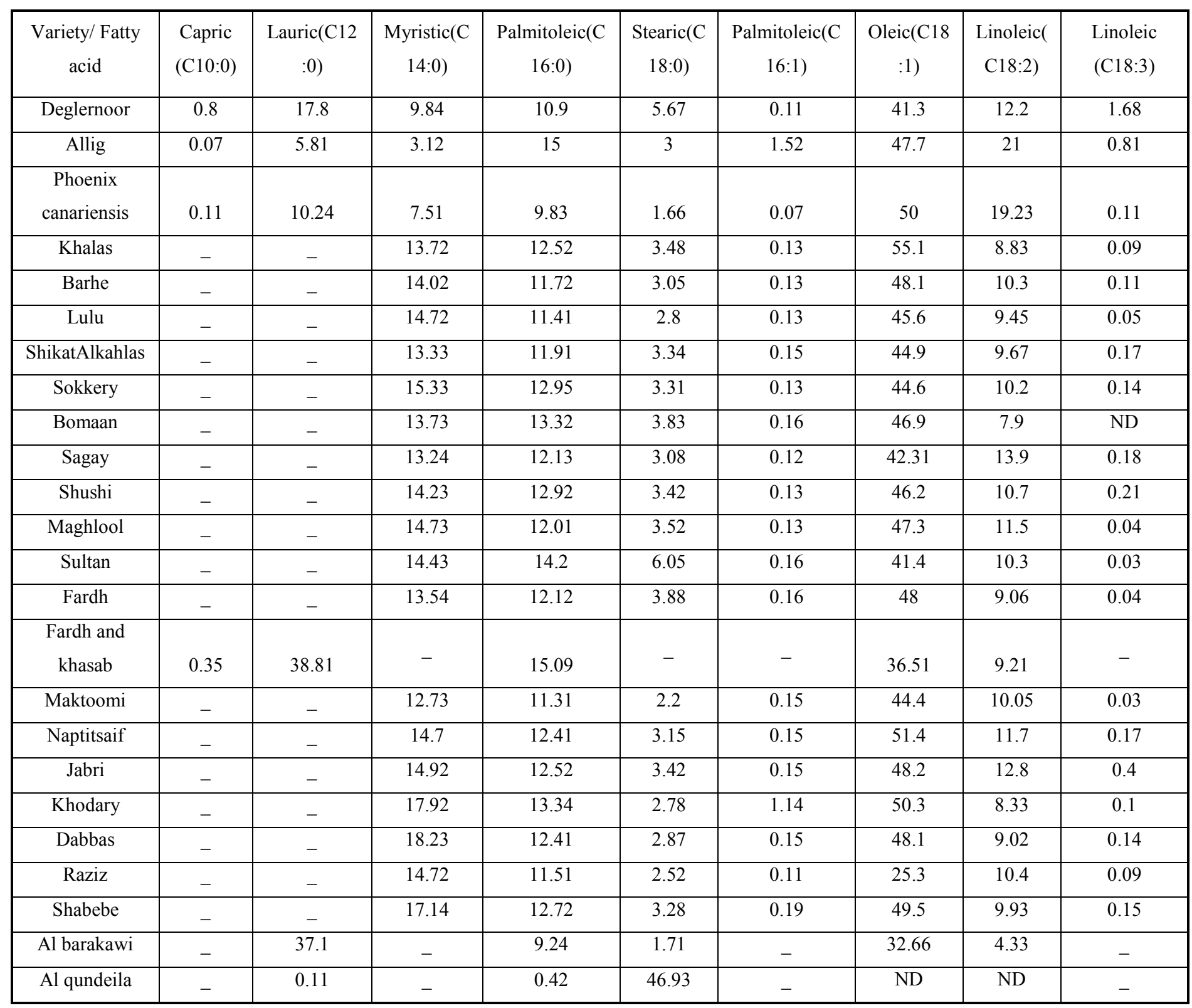

\subsection{Date as armature filter medium}

The process of water absorption by date pits was modeled and analyzed using Fick's second law of diffusion, finite element approach, and Peleg model[10].The rate of water diffusion was high during the first two hours of soaking and then gradually decreased. Dates have different chemical composition. The variation comes from two causes or things the type of the date and the geographic location of the dates and also the length of summer period. Table 1 give the type of date and it characteristics. Mabseeli which is number (6) have the lowest moisture content 3.1gm./100gm., Usellah(7) have 4.4gm./100gm., Shahal (8) have 5.2 gm./100gm finally Khalas(1) have 7.5 gm./100gm. This group of dates when grind and soak in water well have less effect on oily soil when the washing starts comparing to other dates. All the dates sample where taken from Sahara desert in morocco. Moisture content is the key factor in cleaning process . The four types of dates with less moisture where sampled from south part of Sahara which is hotter in temperature and long summer period comparing with the rest dates sample which brought from north part of Morocco that have mild temperature and les summer period. This explain the high moisture in the dates of the north part. The dates reaches their equilibrium moisture content of $41 \%$ after 240 hours soaking in distilled water. The date powder could be used 
to remove $90 \%$ phenol and $\mathrm{p}-=$ nitro phenol from water. [11] used date powder to remove dyes (i.e. Methylene blue) from aqueous

\section{Problem Formulation}

In Kuwait, rehabilitation has proceeded regularly, and urban areas were fast restored to their pre-warfare fame, within the outlying wilderness regions, massive-scale environmental pollutants crude oil spilled from more than 700 oil wells destroyed at Kuwait desert. The present study deals with the remediation of hydrocarbon impacted soil, utilizing soil washing technique in the assistance using different concentration of date seeds.

\subsection{Literature review}

[12], [13] soil washing was studied to evaluate the treatability of new River sand infected in the laboratory with a petroleum distillate. Unaltered and base-extracted sands were combined with petroleum hydrocarbons, equilibrated and washed with water or a surfacing at two different values of $\mathrm{pH}(7$ and 12). The surfactant had no significant impact on contaminant elimination efficiencies at neutral ph. Remedy efficiencies of base extracted sand particles have been 10 to $13 \%$ higher than for the unaltered sands. Results suggested that the organic matter played a role in the extent and intensity of hydrocarbon association. Elimination of hemic acids significantly improved TPH removal efficiencies from the sand particles. Use of a nonionic surfactant stepped forward TPH elimination at a $\mathrm{pH}$ of 12. [14] Focus on Total Organic Carbon (TOC) which was used to screen soil samples for petroleum hydrocarbon contamination at a former refinery in Ohio. TOC was measured in the field with wet oxidation using chronic acid and calorimetric.

\subsubsection{Pretreatment}

Pretreatment is achieved to eliminate grossly oversized material and to make a homogeneous feed stream of reasonable size for transport to the soil washing plant. Unit techniques that may be employed are scalping crushing and grinding mechanical screening, jigging and tabling SGS (specific gravity separation) blending and mixing and magnetic substance removal. solution. The degree of removal depends on $\mathrm{PH}$, an adsorbent dose and contact time.

\subsection{Remediation methods}

different methods of remediation of contaminated parent subject (i.e., soil, water) have been proposed and placed to application around the world. One of these approaches applicable to oil contamination is summarized in Figure (4). No one of these remediation ways have $100 \%$ accuracy therefore, the preferred technology is chosen according to site conditions, pollutant concentration, components, and cost.

\subsection{Soil washing method}

Soil washing is a new technique for treating contaminated soil. Washing is applicable for the following items:

- Petroleum and fuel residues.

- Radionuclides.

- Heavy metal.

- Polychlorinated biphenyls (PCBs).

- Pentachlorophenol (PCP).

- Pesticides.

- Cyanides.

- Creosote.

- Volatiles.

\subsubsection{Soil Washing Systems}

Soil washing systems usually consist of the following six distinct process units:

1. Pretreatment.

2. Separation.

3. Coarse-grained treatment.

4. Fine-grained treatment.

5. Process water treatment

6. Residuals management.

\subsubsection{Separation}

Separation systems are designed to make a specific first cut at the chosen interface of course and first-rate grained solids. The cut point is commonly among Sixty-Three and seventy-four microns (230 and two hundred mesh). The two fractions above and below the cut point usually require specific remedy techniques for final cleaning. 


\subsubsection{Coarse-grained treatment}

After the separation step, there may be a small amount of material finer than Sixty-Three to seventy-four microns (230 to $200 \mathrm{mesh}$ ), however it should constitute less than $5 \%$ of the overall solids via weight. In addition, little fine-sized particles will likely be discovered within the water removed in dewatering the coarse-grained fraction. Additional cycling follows and then, this water ought to be sent to the fine-grained treatment technique for healing of these solids. The contaminants of interest will be observed predominantly inside the finer solids, but the coarse fraction may require treatment to eliminate any pollution that is adsorbed on or coats the solids.

\subsubsection{Fine-grained treatment}

At the start of fine-grained treatment, this fraction is now finer than 63 and 74 microns (230 and two hundred mesh) and typically consists of a considerable proportion of solids within the colloidal variety 6 to $10 \mathrm{um}$. Further, the solids concentration, coming in the main from the cyclone overflow in the separation step, could be dilute, as little as five to ten $\%$ solids by using weight. The solids will settle slowly, and a few will no longer settle in any respect due to their clay and colloidal nature.

\subsubsection{Process Water Treatment}

Contaminated wash water may result from the soil washing procedure. This wash water will comprise a few or all the following substances and contaminants:

- Some coarse-grained sands, from 360 um (40 mesh) right down to sixty-three um (230 mesh) there may be little, or no contaminants connected to those solids.

- Fine grained solids 63 um (230 mesh) - these solids will still include attached contaminants and colloidal silt and clay material

- Dissolved salts, which are present within the unique soil, likely sodium and chlorine-containing compounds.

- Organic - Hemic compounds (leaves, twigs, roots, etc.), should be eliminated to appropriate ranges.
- $\mathrm{pH}$ price should be changed to the ideal range for either recycle or disposal.

- Dissolved or solubilized heavy metals requiring treatment and elimination and.

- Different contaminants, such as, free-floating petroleum hydrocarbons requiring elimination.

\subsubsection{Residuals management}

The quantities of merchandise and residual substances generated via a soil washing plant will range at once in proportion to the grain size distribution of primary feed material to be processed. The portions of these streams may be unexpectedly estimated via the bench scale wet sieve evaluation and elutriation technique (up flow classification).Contaminated fines that resulting from the system can be disposed of in a regulated landfill and/or require further remedy through one or a combination of the following treatment technology in order to permit disposal in an environmentally safe and appropriate manner. Incineration low temperature thermal desorption chemical extraction/ bioremediation solidification/ stabilization or verification.

\section{Problem Solution}

\subsection{Methodology}

\subsubsection{Material and methods}

The soil used in this project was obtained from Raudhatian oil field. Distilled water (Milli-Q) was used for the analysis. Date seeds were separated from the fruits and washed and dried in the sun for 24 hours, different dates were obtained from morocco desert.

\subsubsection{Laboratory test}

Samples were analyzed in laboratories of engineering college and labs of science college in Kuwait university.

\subsubsection{INSTRUMENTATION}

\section{i) TOC Analysis of Soil}

TOC Analysis of soil samples were performed using the instrument (TOC -SSM-5000A) solid module. The instrument is calibrated in the range $0-50000 \mathrm{ppm}$ concentration prior to 
sample analysis using minimum five standards prepared using potassium Hydrogen Phthalate Standard contained $47 \%$ carbon and deionized water. A calibration curve was made satisfying satisfies the condition $r>0.995$. The standard response. The sample were homogenized well with mortar and pestle, approximately $100 \mathrm{mg}$ (of contaminated S0.1) weighed in to pare-cleaned ceramic plate. The inorganic carbon was removed from the sample by acidification with few drops of $2 \mathrm{M}$ HCL till the for effervescence stops. The samples then dried in drying oven at $105^{\circ} \mathrm{C} 10$ minutes or until its dries tungsten Oxide is added. Pre-cleaned ceramic wool then placed over the entire sample in the boat to prevent splattering in the $900^{\circ}$ Coven. The sample then analyzed by software against the generated curve to determine the concentration. If sample is highly concentrated, sample amount is reduced accordingly and entered the software.

\section{ii) TOC Analysis of Water}

TOC Analysis of water samples were performed using the instrument (TOC VCPH) TOC Analyzer. The instrument was calibrated in the range $0-20 \mathrm{ppm}$ concentration prior to sample analysis using minimum five standards. Potassium Hydrogen Phthalate Standard used with $47 \%$ carbon content, deionized water and a calibration curve is generated at $r>0.0995$. The standard response and background contamination is measured periodically before sample analysis. The sample is analyzed in triplicate and evaluated by the software against the generated curve and concentration. The percentage moisture of samples is determined separately for the correction of the moisture content. If samples are highly concentrated, sample dilution is performed and entered in the software so that the response fits in the calibration range. In table 3Several tests were done on the lab for the contaminated samples in order to examine the effective soil washing method. The contaminated soil was divided into three groups, each group contains three samples. Each sample contain $100 \mathrm{~g}$ of contaminated soil and $1 \mathrm{~L}$ of distilled water and different portion of date seeds $(0.50$ and 100) g. Each group was divided to three-test period (1-day, 3 day and 5-day, Table 3 ).

\section{iii) Sample testing}

Samples were placed into $50 \mathrm{ml}$ flasks and shaken at $150 \mathrm{rpm}$ for (1, 3 and 5 days) at room temperature, then samples KF to set by gravity, after that the soil was separated from water. The oil content was measured the efficiency of soil wash method and date seeds for soil washing and date seeds efficiency method.

\section{iv) Waste Water}

Wastewater generated from the soil washing was analyzed to find out the level of TOC in the water.

\subsection{Results and Discussion}

The wastewater in the flasks represent a disposal area for the soil contaminated with oil when soil washed by date seeds as shown in figure 3 . The hydrocarbons practically took the contaminate from the soil particles and dump it in the water or the distilled water, later on this oil become part of the water particles. In general, the amount of date seeds and time sequence play a major role in removing oil form soil, in other words cleaner soil percentage wise. The chemical composition of the date seeds is the key for the removal of the oil from the soil. The date has the same combination of in both experiment the 50 gm. and $100 \mathrm{gm}$. As mentioned above this is a variation in the moisture of the different types of dates. The moisture needs more time to start the removal of the hydrocarbons from the soil this was shown after 5 days with the $100 \mathrm{gm}$. From the seeds it cleaned up about $77 \%$ of the contaminants of the soil, also the acid in the date seems to be the second factor in the cleaning process with the help of the Wight(100gm) and the time good result can be seen in the washing process. Figure 7 showed correlation between moisture date seeds and dates type. 


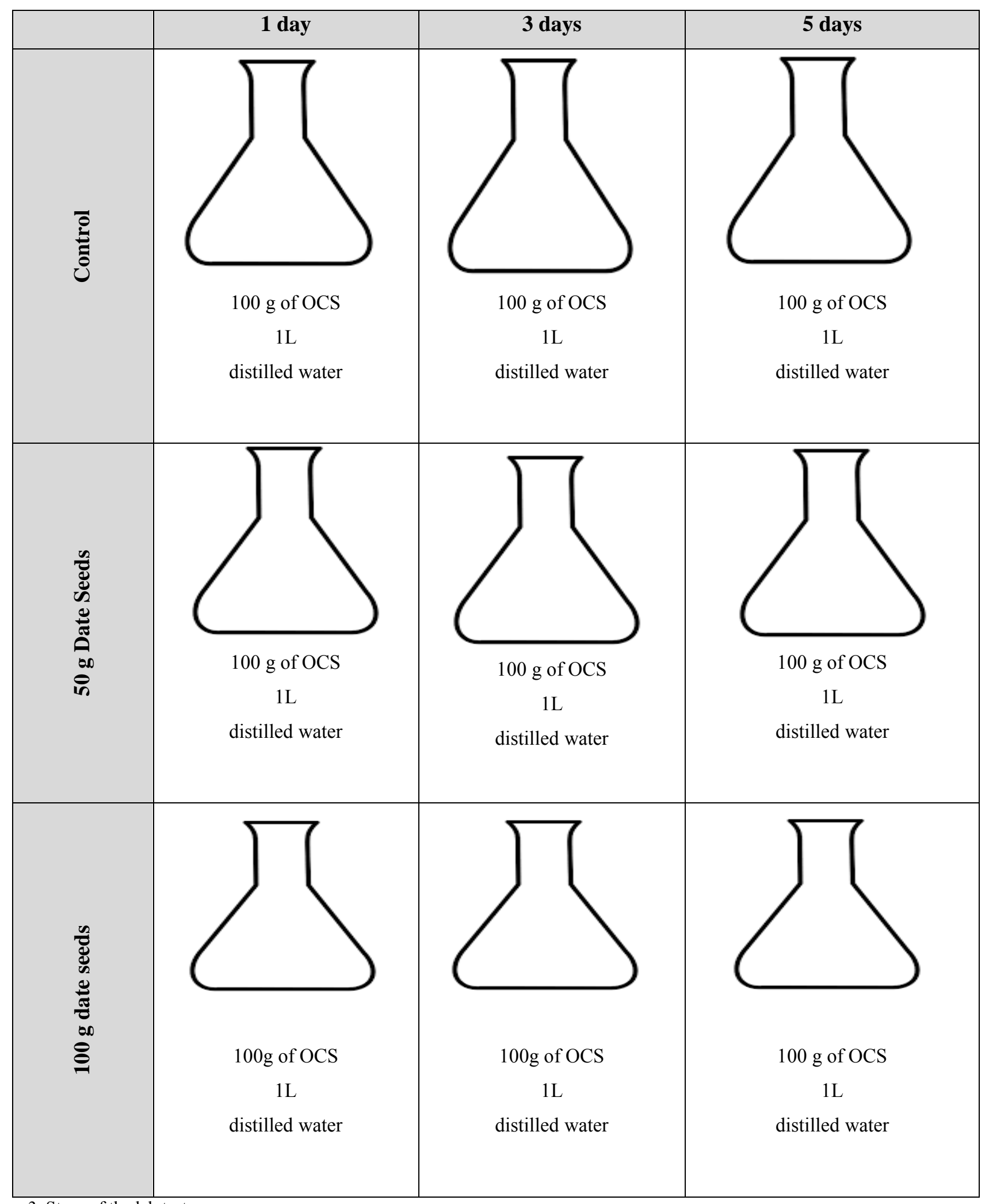

Figure 3. Steps of the lab test. 


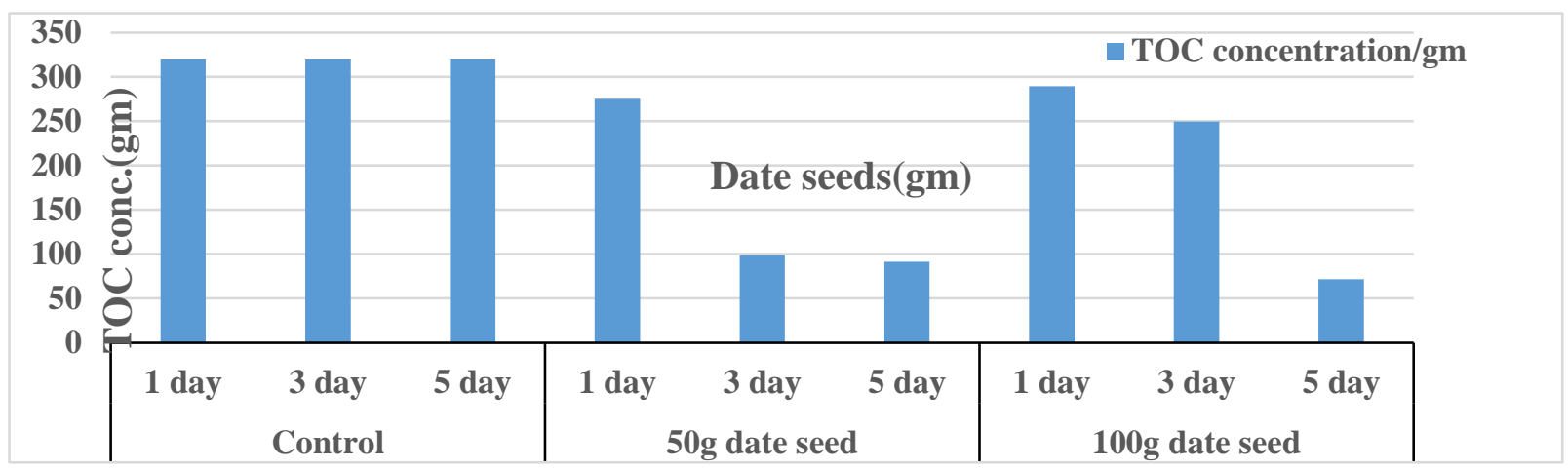

Figure 4. TOC Concentration/gm against time duration.

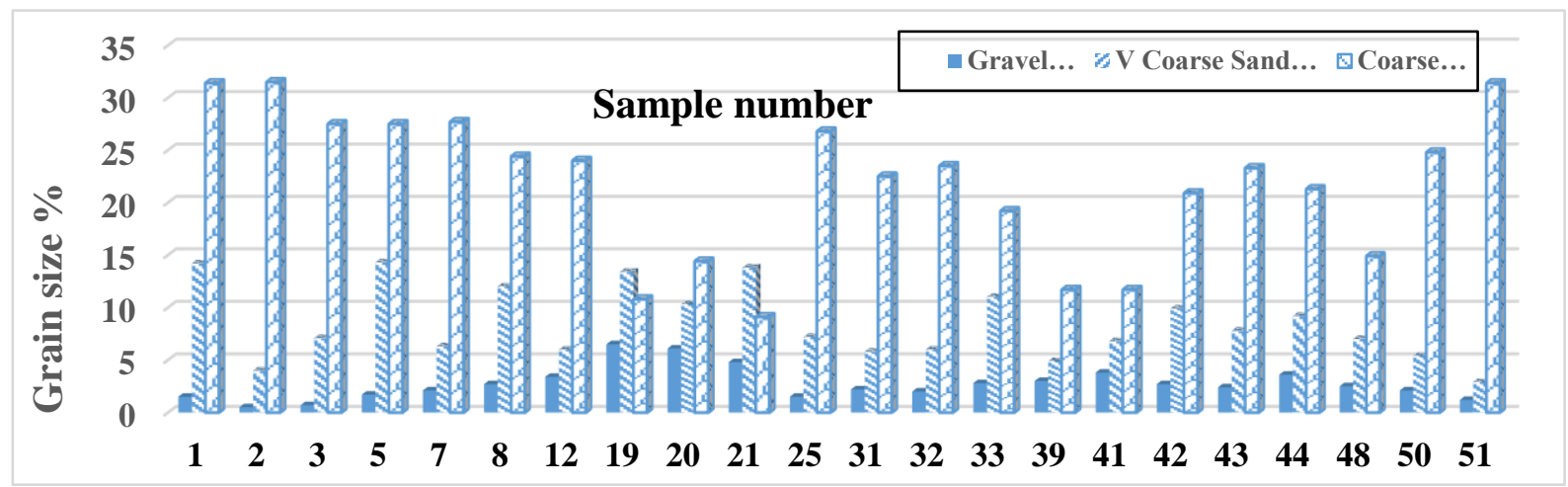

Figure 5. Grain Size Analysis/ Raudatin oil field

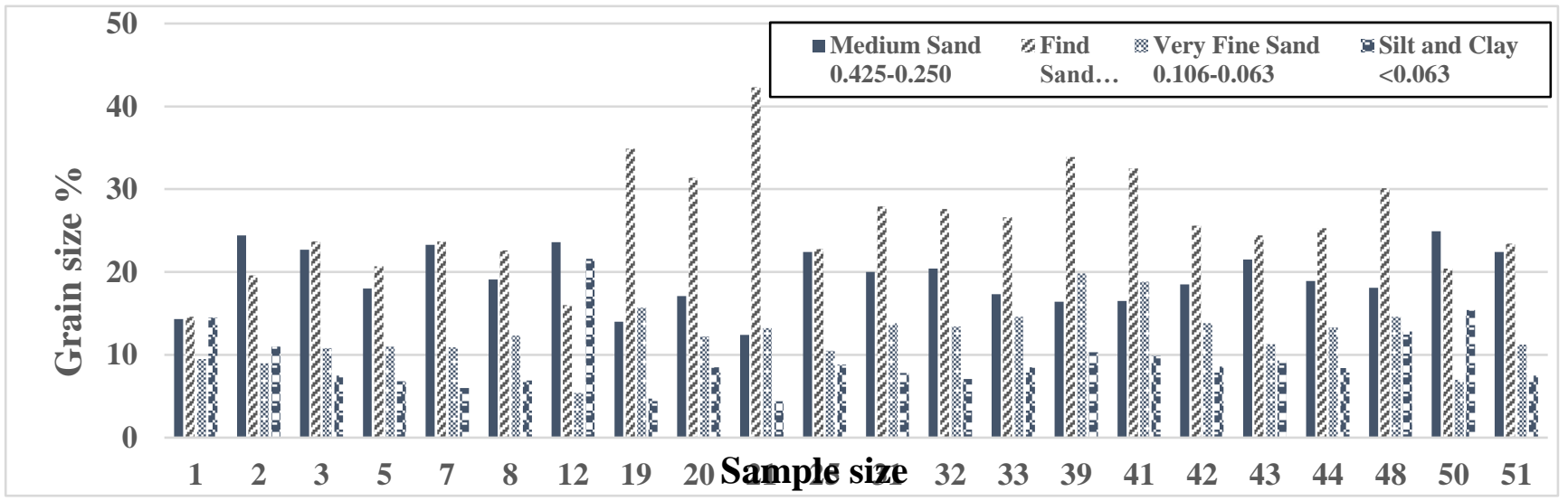

Figure 6. Grain size Analysis/Raudatain oil filed 


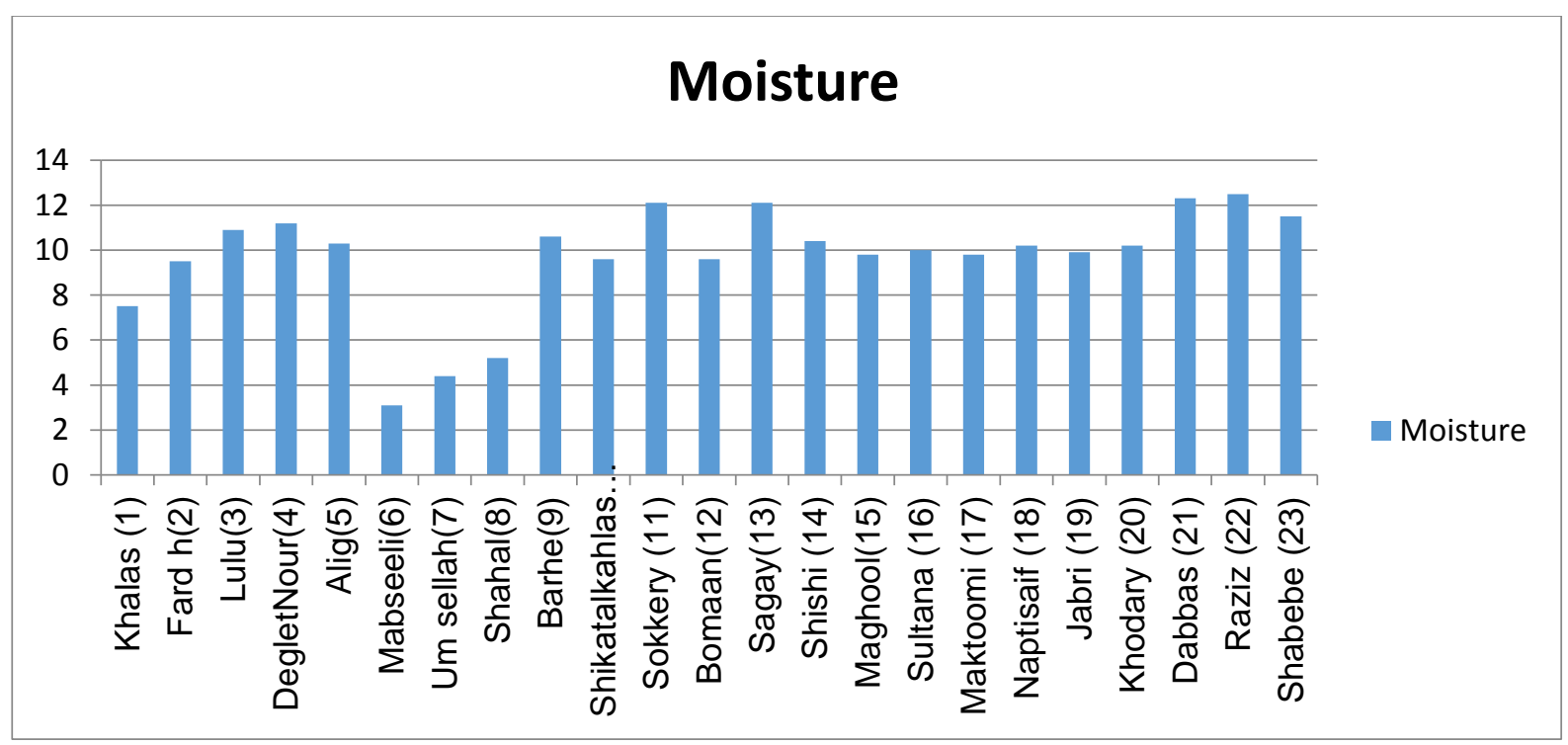

Figure 7. Correlation between moisture date seeds and dates type.

Table 3 summarize the total organic carbon (TOC) concentration after soil washing for the periods of one, two and three days for the control and date seeds. The control distilled water (has no date seeds) results for day one was $319925 \mathrm{mg} / \mathrm{g}$ soil the hydrocarbon removal was $.058 \% 319896 \mathrm{mg} / \mathrm{g}$ soil for day three the removal was $0.067 \%$ and finally in the fifth day the TOC concentration was $319680 \mathrm{mg} / \mathrm{g}$ soil and the removal was $0.13 \%$ (Table 3). Date seeds trigger the drop in TOC concentration in the wastewater. In day one the removal value was $14 \%(2752851 \mathrm{mg} / \mathrm{g}$ soil $)$, in day three $69 \%$ (TOC concentration $98714.29 \mathrm{mg} / \mathrm{g}$ soil) for day five the removal was $71 \%$ (TOC concentration $91642 \mathrm{mg} / \mathrm{g}$ ). This observation was for $50 \mathrm{gm}$ date. When the date seeds doubled (100 gm.) the removal in day one $9.58 \%(289428 \mathrm{mg} / \mathrm{g}$ soil of TOC concentration), for the three days the removal values were $22 \%$ (TOC concentration 249642 $\mathrm{mg} / \mathrm{g}$ soil sample). For five days There were significant removal values with $77.5 \%$ (TOC concentration $717143 \mathrm{mg} / \mathrm{kg}$ soil sample). (3A-B). From the data presented in Table 4, date seeds are effective technique for cleanup soil contaminated by hydrocarbons. In addition, the table shows clearly that there is a strong relationship between the amount of date seeds and the degradation rate of hydrocarbons, high concentration of date seeds is active for cleanup soil mixed by hydrocarbons. Fifty grams removed $71 \%$ of oil in the soil, with $100 \mathrm{gm}$. of date seeds removed more oil only after 5 days but not with one day or three days comparing to the $50 \mathrm{gm}$ date seeds, (figure 4)This was the first observation. The second observation is time sequence. In the fifth day for both 50 and 100 gm. of date seeds, the seeds work it a way of clean up the dirty soil by hydrocarbons. This explain that $100 \mathrm{gm}$. of date seeds $77.5 \%$ of oil was removed, Table 3.

Table 3. Summary for the TOC concentration of soil and removal TOC $\%$.

\begin{tabular}{|c|c|c|c|}
\hline & Period & $\begin{array}{c}\text { TOC Concentration } \\
(\mathbf{m g} / \mathbf{g} \text { Soil })\end{array}$ & Removal Value \% \\
\hline \multirow{3}{*}{ Control } & 1 day & 319925 & $0.06 \%$ \\
\cline { 2 - 4 } & 2 day & 319896 & $0.07 \%$ \\
\cline { 2 - 4 } & 3 day & 319680 & $0.13 \%$ \\
\cline { 2 - 4 } $\mathbf{5 0}$ g date seed & 1 day & 275285.71 & $14 \%$ \\
\cline { 2 - 4 } & 2 day & 98714.29 & $69 \%$ \\
\hline $\mathbf{1 0 0}$ g date seed & 1 day & 91642 & $71 \%$ \\
\hline
\end{tabular}




\begin{tabular}{|l|c|c|c|}
\hline & Period & $\begin{array}{c}\text { TOC Concentration } \\
(\mathbf{m g} / \mathbf{g} \text { Soil) }\end{array}$ & Removal Value \% \\
\hline \multirow{2}{*}{} & 2 day & 249642 & $22 \%$ \\
\cline { 2 - 4 } & 3 day & 71714.3 & $77.50 \%$ \\
\hline
\end{tabular}

\section{Conclusion.}

Soil washing or soil scrubbing is a water based process for remediation of contaminated soils. Date seeds are chemically usable in soil remediation. With increasing amount of date seeds, moisture acidity and time of the cleaning process become faster. Timing can accelerate the mechanism of soil washing.

\section{Recommendation}

A. Remediation by soil washing is a new approach for cleanup soil. Studies that are more detailed needed for this remedy producer.

B. Understanding the chemical composition of the date seeds will explain the mechanism of extraction the hydrocarbon by the date seeds.

C. Farther lab test needed between the grain size morphology of the contaminated soil and soil washing date seeds.

D. Mathematical model might need to be developed between washing time, the quantity of date seeds and the area soil contamination.

E. The cost of remediation by the date seeds should be considered in any soil cleaning plans.

F. This is preliminary study for soil washing mechanism by dates seeds, more investigation by the authors taking in consideration all the recommendation mentioned above.

\section{Acknowledgement}

The authors are very thankful to the Interested Parties for providing cooperation and support for carrying out the present study.

\section{References :}

1. Al-Sarawi, M. A., El-Baz, F., and Koch, M. "Geomorphologic controls on surface deposits of Kuwait as depicted in satellite images", Kuwait
Journal of Science and engineering, Vol. 33, No. 2, pp. 123, 2006.

2. Khalaf F.I, Misak ,R., and AlDousari ,A.," Sedimentological and morphological characteristics of some nabkha deposits in the northern coastal plain of Kuwait, Arabia", Journal of Arid Environments, Vol. 29, Iss 3, Pp 267-292, 1995.

3. Survey of Technology for Remediation of Oil-Contaminated Soil in Kuwait. www.pecj.or.jp/japanese/report/reserc h/report-pdf/H11_1999/99surv8.

4. Al-Farsi, M., and C. Y. Lee. "Optimization of phenolics and dietary fibre extraction from date seeds", Food Chemistry. Vol., 108, pp. 977985, 2008.

5. Sirisena, S., Ng, K., and Ajlouni, S. "The Emerging Australian Date Palm Industry: Date Fruit Nutritional and Bioactive Compounds and Valuable Processing By-Products", Comprehensive Reviews in Food Science and Food Safety, Vol. 14, 813-823, 2015.

6. Yusuff, K.B., Emeka, P.M., and Attimarad, M., "Concurrent Administration of Date Palm Fruits with Lisinopril Increases Serum Potassium Level in Male Rabbits", International Journal of Pharmacology,Vol.14, Iss. 1, pp. 9398, 2018.

7. 7.Besbes, S., Blecker, C.,Deroanne, C., Lognay G., Drira N.E., and AttiaH.:"Quality Characteristics and Oxidative Stability of Date Seed Oil During Storage", Food Science and Technology International, Vol.10,iss. 5, pp. 333-338,2004.

8. Besbes S., Drira L., Blecker C. , Deroanne C, and Attia H., "Adding value to hard date (Phoenix dactylifera L.): Compositional, functional and sensory characteristics of date jam", 
Food Chemistry, Vol. 112, Iss 2, , Pages 406-411,2009.

9. Hossain, M. Z., Waly, M. I., Singh, V., Sequeira, V., and Rahman, M. S. "Chemical composition of date-pits and its potential for developing valueadded product-a review".Polish journal of food and nutrition sciences, Vol. 64 No. 4, pp. 215-226., 2014.

10. Waezi-Zadeh, M., Ghazan fari, A, and Noor bakhsh, S., "Finite element analysis and modeling of water absorption by date pits during a soaking process", Journal of Zhejiang University-SCIENCE B, Biomedicine and Biotechnology, Vol. 11, No. 7, pp.482-488, 2010.

11. Ahmed M.J. and Theydan S.K., "Equilibrium isotherms, kinetics and thermodynamics studies of phenolic compounds adsorption on palm-tree fruit stones", Ecotoxicological and Environmental Safety, Vol. 84, pp.3945, 2012.

12. Bhandari, A., Novak, J. T., and Dove, D. C.."Effect of soil washing on petroleum-hydrocarbon distribution on sand surfaces", Journal of Hazardous Substance Research, Vol.2, No.7, pp.1-13, 2000.

13. Schreier, C. G., Walker, W. J., Burns, J., and Wilkenfeld, R., "Total organic carbon as a screening method for petroleum hydrocarbons". Chemosphere, Vol.39, No. 3, pp.503510., 1999.
14. Radek Jurcik, Legal and Economic Instruments of Environmental Protection in the Area of Air Protection - Example of Selected Regions of the Czech Republic and Impacts on Entrepreneurs, WSEAS Transactions on Business and Economics, pp. 508-513, Volume 16, 2019

15. Aram Hanna Massoudi, Sahar Jalal Fatah, Mohamed Essam Ahmed,Incorporating Green Innovation to Enhance Environmental Sustainability, WSEAS Transactions on Business and Economics, pp. 477486, Volume 16, 2019

16. St. Dwiarso Utomo, Zaky Machmuddah, Melati Oktafiyani, The Associations Between Earnings Management, Corporate Environmental Disclosure, Corporate Financial Performance and Corporate Governance Mechanisms, WSEAS Transactions on Business and Economics, pp. 345-354, Volume 16, 2019.

Creative Commons Attribution License 4.0 (Attribution 4.0 International, CC BY 4.0)

This article is published under the terms of the Creative Commons Attribution License 4.0 https://creativecommons.org/licenses/by/4.0/d eed.en_US 